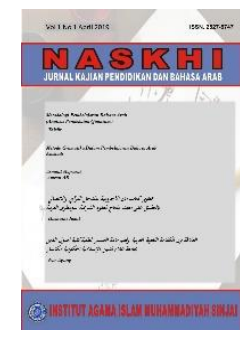

\title{
NASKHI
}

Jurnal Kajian Pendidikan dan Bahasa Arab

Volume 2, No. 2, 2020

ISSN (print) : 2527-5747

ISSN (online) : 2716-3369

Homepage : https://journal.iaimsinjai.ac.id/index.php/naskhi

\section{PROBLEMATIKA PEMBELAJARAN MUHADATSAH MAHASISWA PENDIDIKAN BAHASA ARAB (PBA) DI IAI MUHAMMADIYAH SINJAI}

\author{
A. Mustika Sari, Ismail, Sardiyanah \\ Institut Agama Islam Muhammadiyah Sinjai \\ andimustikasari5@gmail.com
}

\begin{abstract}
Arabic language has long developed in Indonesia, but it seems that learning Arabic until now has not escaped the problem. One of them is the problem of learning muhadatsah. The problem arises in students because of a lack of mastery of vocabulary making it difficult to speak Arabic. As for the solution to Dealing with The Problem of Muhadatsah Learning is to master more vocabulary, there needs to be a habituation of speech, and the means and previews must be adequate.
\end{abstract}

Keywords: Problematika Learning Muhadatsah - Arabic Language Education Student

\section{Abstrak}

Bahasa arab telah lama berkembang di Indonesia, akan tetapi tampaknya mempelajari bahasa Arab sampai sekarang tidak luput dari problem. Salah satu diantaranya adalah problematika pembelajaran muhadatsah. Problematika itu muncul pada mahasiswa karena kurangnya penguasaan kosakata sehingga susah untuk bercakap bahasa Arab. Adapun solusi untuk Mengahadapi Problematika Pembelajaran Muhadatsah yaitu menguasai kosakata yang lebih banyak, perlu adanya suatu pembiasaan berbicara, serta sarana dan prasaran harus memadai.

Kata Kunci: Problematika Pembelajaran Muhadatsah - Mahasiswa Pendidikan Bahasa Arab 


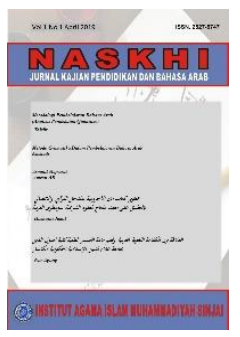

\section{NASKHI}

Jurnal Kajian Pendidikan dan Bahasa Arab

Volume 2, No. 2, 2020

ISSN (print) : 2527-5747

ISSN (online) : 2716-3369

Homepage : https://journal.iaimsinjai.ac.id/index.php/naskhi

\section{A. PENDAHULUAN}

Bahasa Arab merupakan bagian dari bahasa asing. Bahasa Arab juga merupakan bahasa sains dan teknologi yang memiliki kedudukan yang sangat istimewa serta diperhitungkan sehingga bahasa Arab dijadikan salah satu bahasa internasional. Selain itu, bahasa Arab juga merupakan bahasa ummat islam, dan untuk memahami islam dengan benar, sebagai seorang muslim sejati seyogyanya memahami dan mengerti bahasa Arab dengan benar (WA, 2011)

Mempelajari bahasa Arab adalah bagian dari din (agama), hukum mempelajarinya wajib bagi umat Islam yang mampu dan bertanggung jawab atas tersebarnya Islam di permukaan muka bumi ini, karena tidak mungkin memahami dinul-Islam dengam pemahaman yang benar melainkan dengan bahasa Arab (Rofiq, 2007). Dalam mempelajari bahasa Arab ada empat keterampilan berbahasa yaitu keterampilan menyimak, keterampilan berbicara, keterampilan membaca, dan keterampilan menulis. Namun ke empat jenis keterampilan tersebut tidaklah harus dikuasai oleh mahasiswa. Tetapi tergantung pada hakikatnya dari pengajaran bahasa Arab itu sendiri.

Bahasa arab telah lama berkembang di Indonesia, akan tetapi tampaknya mempelajari bahasa Arab sampai sekarang tidak luput dari problem. Salah satu diantaranya adalah problem (masalah) dalam muhadatsah pada saat proses pembelajaran bahasa Arab berlangsung (WA, 2011). Problem muhadatsah itulah yang dihadapi mahasiswa pendidikan bahasa Arab angkatan 2018, karena mahasiswa pendidikan bahasa Arab yang berlatar belakang Sekolah Menengah Atas (SMA) pada awal perkuliahan memang sulit dalam menangkap pembelajaran apalagi pembelajaran muhadatsah, karena waktu duduk di bangku sekolah sebagai pelajar mahasiswa tidak mendapatkan pembelajaran Muhadatsah. Dan setelah masuk keperguruan tinggi mengambil jurusan pendidikan bahasa Arab dimana mahasiswa tersebut harus diberhadapkan dengan pembelajaran Muhadatsah. Para mahasiswa di tuntut untuk menggunakan bahasa Arab langsung yang hanya alokasi waktunya yang begitu singkat. Meskipun ada beberapa mahasiswa yang sebelumnya tidak mendapatkan pelajaran tersebut terutama dari Sekolah Menegah Atas (SMA). Dalam pembelajaran Muhadatsah itulah tidak mungkin terlepas dari faktor-faktor problematika pembelajaran.

Peneliti lakukan proses pembelajaran bahasa Arab pada mahasiswa pendidikan bahasa Arab (PBA) di IAI Muhammadiyah Sinjai ini belum sepenuhnya memenuhi harapan sebagaimana target yang di harapkan. Motivasi dan minat mahasiswa yang rendah dalam mempelajari bahasa Arab dipengaruhi oleh berbagai faktor, salah satu di antaranya adalah penggunaan metode pengajaran yang tidak tepat, sehingga menjadikan mahasiswa semakin kesulitan mempelajari bahasa Arab (Agung, 2020). Dalam mempelajari bahasa Arab dituntut penguasaan empat maharoh yaitu mendengar (Istima'), berbicara (Kalam), membaca (Qira'ah) dan menulis (Kitabah).

Salah satu kekurangan yang tampak jelas dalam pembelajaran muhadatsah adalah kurangnya penguasaan kosa kata. Berkaitan dengan 


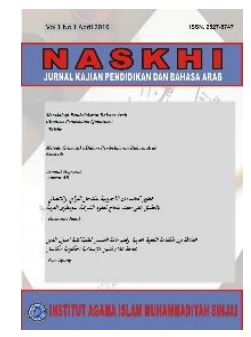

\section{NASKHI}

Jurnal Kajian Pendidikan dan Bahasa Arab

Volume 2, No. 2, 2020

ISSN (print) : 2527-5747

ISSN (online) : 2716-3369

Homepage : https://journal.iaimsinjai.ac.id/index.php/naskhi

problematika kosa kata tersebut perlu diketahui bahwa banyak segi-segi sharaf (morfologi) dalam bahasa Arab yang tidak terdapat dalam bahasa Indonesia, semisal konjugasi (tashrif). Contoh konjugasi dalam bahasa Arab yang dapat diberikan adalah fi'il madhi (kata kerja bentuk lampau) كَتَب yang untuk bentuk fi'il

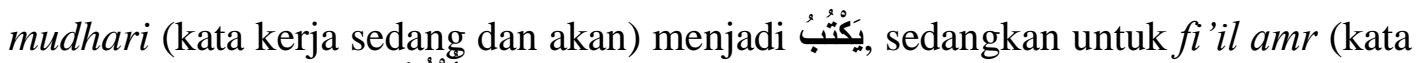
kerja perintah) menjadi أَكْتَبْ (Izzan, 2004).

Dalam morfologi bahasa Arab, hal-hal yang telah diuraikan di atas tidak ada bandingannya atau persamaannya dalam bahasa Indonesia. Karena itu, persoalan-persoalan tersebut harus dipelajari secara cermat dan jelas. kedudukannya sebagai hal-hal yang kompleks dan tidak mudah dimengerti karena dari perubahan bentuk kata petama, kedua, dan ketiga tersebut membawa perubahan arti yang berbeda ketika digunakan dalam sebuah kalimat.

Mahasiswa pendidikan bahasa Arab yang kebanyakan dari pondok pesantren semestinya bercakap bahasa Arab di dalam ruangan karena disitulah merupakan salah satu wadah untuk mempraktekkan berbahasa dalam kehidupan sehari-hari agar mahasiswa yang awam sekali dengan bahasa Arab akan terbiasa dalam berbicara bahasa Arab. Mahasiswa tidak menggunakan lagi bahasa Indonesia dan bahasa Bugis ketika di dalam ruangan, meskipun perkuliahan hanya tiga hari per minggu.

Pembahasan problematika diatas dapat di simpulkan beberapa pertanyaan yakni bagaimana problematika pembelajaran muhadatsah pada mahasiswa pendidikan bahasa Arab (PBA) angkatan 2018 di IAI Muhammadiyah Sinjai?. Bagaimana solusi terhadap problematika pembejaran muhadatsah mahasiswa pendidikan bahasa Arab (PBA) di IAI Muhammadiyah Sinjai?

\section{B. METODE PENELITIAN}

\section{Desain Penelitian}

Penelitian ini penulis memilih jenis penelitian yang akan di pakai adalah fenomologi. Penelitian yang akan dilakukan oleh penulis adalah penelitian fenomonologis dengan memberikan gambaran secara valid, reliabel, dan objektif.

\section{Teknik Pengumpulan Data}

Teknik atau metode yang digunakan untuk mengumpulkan data penelitian adalah:

a. Observasi yaitu metode yang dilakukan dengan cara pengamatan dan pencatatan secara sistematis terhadap gejala yang tampak pada obyek penelitian. Penelitian ini penulis menggunakan metode observasi non partisipan, yaitu peneliti tidak terlibat dan hanya sebagai pengamat independen. Metode ini digunakan untuk mengamati problematika pemebelajaran muhadatsah mahasiswa pendidikan bahasa Arab (PBA) angkatan 2018 di IAI Muhammadiya Sinjai.

b. Wawancara yaitu proses memperoleh keterangan untuk tujuan penelitian dengan cara tanya jawab sambil bertatap muka antara pewawancara dan informan atau orang yang diwawancarai, dengan atau tanpa menggunakan pedoman (guide) wawancara, dimana pewawancara dan informan terlibat 


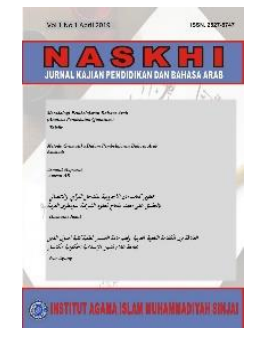

\section{NASKHI}

Jurnal Kajian Pendidikan dan Bahasa Arab

Volume 2, No. 2, 2020

ISSN (print) : 2527-5747

ISSN (online) : 2716-3369

Homepage : https://journal.iaimsinjai.ac.id/index.php/naskhi

\section{Sumber Data}

dalam kehidupan sosial yang relatif lama (Bungin, 2009). Adapun data yang di dapat pada wawancara yaitu problematika pembelajaran muhadatsah mahasiswa pendidikan bahasa Arab (PBA) angkatan 2018 di IAI Muhammadiyah Sinjai.

c. Dokumentasi yaitu peniliti menganalisis nilai yang diperoleh mahasiswa pendidikan bahasa Arab angkatan 2018. Nilai yang dianalisis tersebut di peroleh dari pihak lembaga IAI Muhammadiyah Sinjai serta gambar atau rekaman penelitian.

Data penelitian diperoleh dari lembar observasi dan pedoman wawancara kepada mahasiswa pendidikan bahasa Arab (PBA) angkatan 2018 di IAI Muhammadiyah Sinjai.

\section{PEMBAHASAN}

\section{Pembelajaran Muhadatsah}

Pelajaran muhadatsah merupakan pelajaran bahasa Arab yang pertamatama diberikan. Tujuan utama pengajaran bahasa Arab adalah agar mahasiswa mampu bercakap-cakap (berbicara) dalam pembicaraan sehari-hari dengan berbahasa Arab dan membaca Alquran dalam sholat dan doa-doa. Maksud dari berbahasa adalah berbicara lisan (Izzan, 2004).

Muhadatsah pada dasarnya merupakan bagian dari ta'bir syafawi, hanya saja dalam muhadatsah meliputi kemampuan berialog bukan sekedar ta'bir tetapi juga fahm al-mas-mu'. Dengan demikian, aspek yang berkemampuan yang harus dimiliki agar mampu berdialog adalah dapat mendengarkan secara baik, memahami setiap ungkapan yang ditangkap, fasih dalam melafalkan kata per kata dan mampu menyusun kalimat dengan baik sehingga dapat dipahami lawan bicaranya (Munir, 2017). Namun dalam aktivitas berbicara ini sebenarnya sangat menarik, akan tetapi sering terjadi sebaliknya, yaitu suasana menjadi kaku dan akhirnya macet. Hal ini terjadi disebabkan penguasaan kosa-kata mahasiswa sangat minim karena menguasai kosakata mahasiswa membutuhkan waktu yang berbeda-beda, karena ada yang cepat ingatannya dalam menghafal kosakata dan adapun yang lambat. Maka pendidik bahasa Arab tidak memiliki kompetensi komunikatif aktif, bahkan mahasiswa kurang berani mengekspresikan kompetensinya karena takut salah.

Secara umum, keterampilan berbicara bertujuan agar para pelajar mampu berkomunikasi secara lisan dengan baik dan wajar (Nuha, 2012). Tujuan dari pembelajaran muhadatsah mencakup beberapa hal antara lain:

1. Kemudahan berbicara

2. Kejelasan, dalam hal ini peserta didik berbicara dengan tepat dan jelas, baik artikulasi maupun diksi kalimat-kalimatnya.

3. Bertanggung jawab, latihan berbicara yang bagus menekankan pembicara untuk bertanggung jawab agar berbicara secara tepat. 


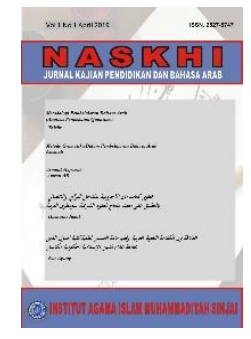

\section{NASKHI}

Jurnal Kajian Pendidikan dan Bahasa Arab

Volume 2, No. 2, 2020

ISSN (print) : 2527-5747

ISSN (online) : 2716-3369

Homepage : https://journal.iaimsinjai.ac.id/index.php/naskhi

4. Membentuk pendengaran yang kritis, latihan berbicara yang baik sekaligus mengembangkan keterampilan menyimak secara kritis juga menjadi tujuan utama program pembelajaran ini.

5. Membentuk kebiasaan, kebiasaan ini bisa diwujudkan melalui interaksi dua orang atau lebih yang telah di sepakati sebelumnya, tidak harus dalam komunitas besar.

Ada beberapa aspek yang perlu di perhatikan oleh pengajar dalam pembelajaran muhadatsah, antara lain:

a. Dalam melatih percakapan, pengajar hendaknya memberikan contoh terlebih dahulu dengan intonasi dan ekspresi yang benar-benar menggambarkan pengertian secara tepat.

b. Dalam percakapan bebas hendaknya pengajar memberikan perhatian khusus kepada siswa yang pemalu dan kurang berani dalam berbicara.

c. Dalam mengikuti percakapan atau pembicaraan siswa, sebaiknya pengajar bersabar untuk tidak terburu-buru memberikan pembetulan setiap kali siswa berbuat kesalahan.

d. Susunan kelas hendaknya di ubah sedemikian rupa sehingga memungkinkan partisipasi seluruh anggota kelas dalam kegiatan pembelajaran (Musthafa, 2017).

\section{Problematika Pembelajaran Muhadatsah}

Problematika berasal dari kata arab al-mas'alatun - masa'ilu (Munawwir, 2007) problematika dalam arti suatu perkara yang belum dapat diselesaikan. Seperti halnya permasalahan yang terjadi yaitu tidak semua mahasiswa mampu berbicara menggunakan bahasa Arab karena kurangnya percaya diri dalam diri mahasiswa tersebut sehingga mahasiswa tidak selalu berbicara menggunakan bahasa Arab bersama dengan teman mereka di kampus, karena mahasiswa selalu memikirkan kesalahan ketika berbicara bahasa Arab dan mahasiswa juga merasa canggung karena tidak selalu melatih diri mereka setiap saat dalam berbicara bahasa Arab. Biasanya juga mahasiswa melihat situasi di kampus ketika ingin berbicara. Maka perlu pembelajaran dari pendidik sehingga dapat memperhatikan kondisi individu anak, karena merekalah yang mau belajar. Adapun Pembelajaran adalah suatu kombinasi yang tersusun meliputi unsur-unsur manusiawi, material, fasilitas, perlengkapan, dan prosedur yang saling memengaruhi untuk mencapai tujuan pembelajaran (Mursid, 2015).

Adapun hakikat terori pembelajaran adalah sebagai upaya untuk mengaitkan peristiwa pembelajaran eksternal dan hasil belajar dengan menunjukkan bagaimana peristiwa-peristiwa belajar dapat mendukung penigkatan proses pembelajaran internal. Artinya, orientasi teori pembelajaran adalah untuk mengusulkan suatu hubungan secara rasional antara peristiwa belajar, pengaruhnya terhadap proses belajar, dan hasil belajar yang diperoleh dari proses-proses tersebut. Selanjutnya, istilah pembelajaran dapat dipahami melalui dua kata, yakni construction dan instruction. Construction dilakukan 


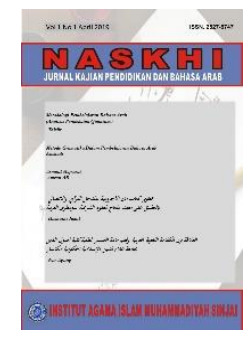

\section{NASKHI}

Jurnal Kajian Pendidikan dan Bahasa Arab

Volume 2, No. 2, 2020

ISSN (print) : 2527-5747

ISSN (online) : 2716-3369

Homepage : https://journal.iaimsinjai.ac.id/index.php/naskhi

untuk peserta didik (dalam hal ini peserta didik pasif), sedangkan instruction dilakukan oleh peserta didik (di sini peserta didik aktif). Maka berbicara dengan problematika pembelajatan Muhadatsah, dalam bercakap-cakap menggunakan bahasa Arab tidak semua mahasiswa mampu dan memanfaatkan lingkungan sebagai sumber belajar dalam pembelajaran Muhadatsah tetapi biasanya mahasiswa bercakap-cakap bahasa Arab di kampus kalau ada tugas. Maka otomatis mahasiswa itu cenderung tidak mampu berbicara bahasa Arab dengan lancar ketika berlatih hanya sekali saja.

Pembelajaran bahasa Arab dengan berbagai karakteristiknya serta motivasi mempelajarinya di kalangan masyarakat non Arab, tetap saja memiliki banyak kendala dan problematika yang dihadapi karena bahasa Arab tetap bukanlah bahasa yang mudah untuk dikuasai total. Problematika yang biasanya mucul dalam pembelajaran bahasa Arab bagi non Arab terbagi ke dalam dua bagian, problematika linguistik dan non linguistik. Termasuk problem linguistik yaitu tata bunyi, kosakata, tata kalimat dan tulisan. Sementara yang termasuk problem non linguitik yang paling utama adalah problem yang menyangkut perbedaan sosiokultural masyarakat Arab dengan masyarakat non Arab (Hermawan, 2014).

Jadi dapat disimpulkan bahwa problematika pembelajaran adalah bahasa arab adalah berbagai masalah yang dihadapi dalam pembelajaran. Sedangkan problematika pembelajaran yang penulis maksud dalam proposal ini adalah berbagai problem atau persoalan yang dihadapi oleh mahasiswa dalam pembelajaran muhadatsah.

\section{Solusi Problematika Pembelajaran Muhadatsah}

Dalam pembelajaran bahasa terutama muhadatsah memang mempunyai beberapa kendala akademik baik dari pihak dosen pengajar dari pihak mahasiswa yang baru belajar. Walaupun problematika itu pada akhirnya dapat diatasi. Adanya problematika dalam pembelajaran bahasa Arab itu dapat dimaklumi karena bahasa Arab itu termasuk bahasa asing, sekalipun itu bahasa agama mereka, tetapi karena bahasa itu asing dengan keseharian mereka, maka bahasa itu dapat di golongkan kedalam komponen bahasa asing, maka untuk mengatasi problematika pembelajaran bahasa Arab. Penulis ingin menyampaikan beberapa solusi untuk mengatasi problematika tersebut. Solusi penulis tawarkan adalah sebagai berikut:

a. Adanya buku-buku bacaan bahasa Arab, Tingkat mahasiswa pemula di perpustakaan. Buku-buku bacaan tingkat pemula itu harus memadai sehingga dosen pengajar langsung menunjukkan buku-buku bacaan tersebut untuk dimiliki atau dipelajari oleh seluruh mahasiswa tingkat pemula. Sebab, kalau hanya bahan ajardari dosen yang bersangkutan bahannya itu hanya terbatas untuk digunakan secara temporal saja. Akan tetapi kalau buku-buku itu sudah tersedia dengan memadai, maka dosen pengajar itu sudah menekankan kepada mahasiswa untuk bisa membaca 


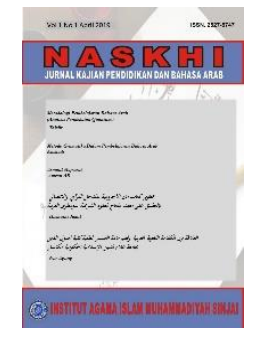

\section{NASKHI}

Jurnal Kajian Pendidikan dan Bahasa Arab

Volume 2, No. 2, 2020

ISSN (print) : 2527-5747

ISSN (online) : 2716-3369

Homepage : https://journal.iaimsinjai.ac.id/index.php/naskhi

dan mempelajari dengan sungguh-sungguh sesuai arahan dosen yang bersangkutan.

b. Adanya fasilitas yang memadai seperti laboratorium bahasa tidak hanya dipermulukkan bagi mahasiswa bahasa inggris dan Arab saja, tetapi untuk mahasiswa yang belajar bahasa arab di prodi yang ada. Paling kurang laboratorium itu untuk dapat memberi sugesti (Tasyji) kepada mahasiswa agar mau mempelajari bahasa Arab itu.

c. Dosen-dosen yang ada di prodi PBA harus ikut memberikan dorongan kepada mahasiswa agar mau dan sungguh-sungguh mempelajari bahasa Arab, karena bahasa itu sebagai sokoguru bagi mata kuliah mata kuliah keislaman lainnya 'ulum Alqur'an dan 'ulum Al Hadits, Tasawuf dan lainlain. Apalagi bagi mahasiswa PBA mereka adalah calon-calon guru bahasa Arab di MTs dan MA yang wajib menguasai dasar-dasar bahasa Arab.

d. Adapun faktor pendukung mempengaruhi proses pembelajaran muhadatsah sehingga kita dapat berbicara bahasa Arab yakni dengan mendengarkan audio-audio bahasa Arab atau nyanyian-nyanyian bahasa Arab kemudian kita mencatat kosakata baru dari suara atau audio berbahasa Arab tersebut kemudian kita cari artinya. Kemudian kosakata yang baru telah kota dapatkan dari audio tersebut kita terapkan pada teman-teman kita itu yang pertama, kemudian yang kedua yakni kita harus berkomunikasi pada teman-teman yang paham berbicara bahasa Arab, kemudian yang ketiga yakni kita harus rajin membaca buku yang berbahasa Arab dan kita harus melatih lidah kita ini supaya tidak terbatabata dalam berbicara bahasa Arab.

e. Pembelajaran muhadatsah yang menjadi tolak ukur adalah harus memperhatikan betul penguasaan mufradat (kosakata), sehingga tidak

\section{PENUTUP} mengalami masalah dalam menyusun kaidah-kaidah dalam bahasa Arab.

Problematika pembelajaran muhadatsah diantaranya tidak semua mahasiswa mampu berbicara menggunakan bahasa Arab karena kurangnya percaya diri, dan kurangnya pemahaman mahasiswa mengenai kosakata yang ada sehingga mengakibatkan mahasiswa sulit menguasai kosakata dengan baik, kurangnya sarana dan prasarana dalam pembelajaran muhadatsah, serta kurangnya kesadaran mahasiswa dalam menggunakan sarana dan prasarana yang ada sehingga mengakibatkan mahasiswa tidak menguasai muhadatsah atau kosakata dengan baik. Sehingga berakibat pada cara komunikasi atau berbicara tidak efektif dala penggunaan bahasa Arab. Selanjutnya yang menjadi problematika pembelajaran Muhadatah, kurangnya kebiasaan mahasiswa berbicara menggunakan bahasa Arab karena terbatasnya waktu belajar di kampus sehingga mahasiswa tidak dapat membiasakan berbicara menggunakan bahasa Arab. 


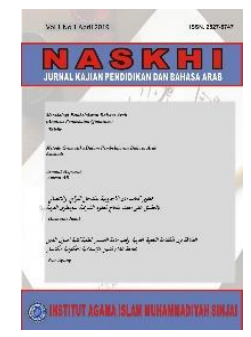

Solusi Problematika Pembelajaran Muhadatsah adalah dengan cara menguasai kosakata yang lebih banyak, terus memahami ilmu nahwu dan sharaf. Kemudian selalu berbicara bahasa arab bersama dengan teman yang fasih bahasa Arabnya.

\section{E. DAFTAR PUSTAKA}

Agung, N. (2020). Peningkatan Kemampuan Debat Bahasa Arab Mahasiswa Melalui Metode Suggestopedia. Jurnal Naskhi: Jurnal Kajian Pendidikan Dan Bahasa Arab, 2(1), 19-29. Retrieved from https://journal.iaimsinjai.ac.id/index.php/naskhi\%0APENINGKATAN

Bungin, B. (2009). Analisis Data Kualitatif: Pemahaman Filosofis dan Metodologis ke Arah Penguasaan Model Aplikasi (III). Jakarta: Rajawali Press.

Hermawan, A. (2014). Metodologi Pembelajaran Bahasa Arab. Bandung: Remaja Rosdakarya.

Izzan, A. (2004). Metodologi Pembelajaran Aahasa Arab. Bandung: Humaniora.

Munawwir, A. W. (2007). Kamus Al-Munawir Indonesia-Arab Terlengkap (I). Surabaya: Pustaka Progresif.

Munir. (2017). Perencanaan Sistem Pengajaran Bahasa Arab Teori dan Prektik. Jakarta: Kencana.

Mursid. (2015). Pengembangan Pembelajaran Paud. Bandung: Remaja Rosdakarya.

Musthafa, S. (2017). Strategi Pembelajaran Bahasa Arab Inovatif. Malang: UINMalang Press.

Nuha, U. (2012). Metodologi Super Efektif Pembelajaran Bahasa Arab. Yogyakarta: Diva Press.

Rofiq, A. (2007). Mukhtarot Qawaidil Lughotil Arobiyyah. Gresik: Pustaka Al Furqan.

WA, M. (2011). Metodologi Pembelajaran Bahasa Arab Teori Dan Aplikasi (I).

Yogyakarta: Teras. 